\title{
Towards future healthcare that is digital by default
}

\section{DOI: $10.7861 /$ fhj.ed-7-3-2}

The digital transformation of healthcare is well underway and will fundamentally change healthcare delivery over the next decade. It is envisioned that this will bridge the gap between an increasing demand for healthcare and the restricted resources to fund it. There have been a number of innovations arising from the COVID-19 crisis. ${ }^{2}$ These digital pioneers value people and behaviours handin-hand with the advances in technology. ${ }^{3,4}$ Further, the recent achievement of HIMSS level 7 in the NHS shows promise and illustrates digital maturity in pockets of excellence. However, these ambitions depicted at policy level require acceptance, trust and systems leadership that we are yet to mainstream. To successfully span this increasing chasm, the healthcare workforce needs to be actively engaged and appropriately skilled. ${ }^{5,6}$ It is without doubt that, in the near future if not already so, healthcare will become digital by default. Digital leaders need to surface at every level of the system and represent 'boots on the ground'? 7,8 Without this, we risk a small group (a so-called 'digital elite') often removed from frontline services shaping the direction of a digitised healthcare service and failing to maximise potential.

The future digital workforce that we imagine is one equipped to integrate digital health technologies into services without compromise to the essence of care. It is key to address how we involve overburdened healthcare workers in this transformation and protect the 'digital health' of our workforce. ${ }^{9}$ We believe this necessitates a strategy that widens recognition and innovation sharing among colleagues in this area: firstly, by making healthcare digital literacy a priority; secondly, by increasing access for all workers to high quality structured career development in this area; and finally, by securing the views of patients and clinicians at the heart of digital transformation.

This is a shared commitment. Professional bodies such as the Royal College of Physicians need to embrace a leadership position to integrate digital and informatics capabilities into the healthcare education system. Therefore, building a digitally ready workforce needs to become a central part of clinical development and delivery of care for clinical and non-clinical leaders alike. We are faced with emerging pathways into digital leadership that are unclear and lack inclusion. This digital health workforce themed issue prioritises diversity as a key component of digital leadership. The Shuri network highlights women across ethnic diversities in digital health and we are delighted to share in their successes during Black History Month (see the inside cover or the online supplementary material).

It is without dispute that a digital revolution is coming, and it is within our power to ensure that everyone is involved and that we leave no one behind.

$\begin{array}{r}\text { Sheena Visram } \\ \text { Associate editor, Future Healthcare Journal } \\ \text { Wajid Hussain }\end{array}$
Clinical director for digital health, Royal College of Physicians
Andrew Goddard
President, Royal College of Physicians

\section{References}

1 Health Education England. The Topol Review: Preparing the healthcare workforce to deliver the digital future. HEE, 2019.

2 Igra A, McGuire H, Naldrett I et al. Rapid deployment of virtual ICU support during the COVID-19 pandemic. FHJ 2020;7:181-4.

3 Kinsella E. Compassion in digital healthcare. FHJ 2020;7:193

4 Patel R. A future of digital leadership that is behavioural by design. FHJ 2020;7:194-5.

5 Farrell D, Sood H. The NHS Digital Academy - learning from the past to look ahead. FHJ 2020;7:185-8.

6 Shah S. Digital health leadership: carving a new pathway. FHJ 2020; 7:199-201.

7 Parrott H. Clinical specialists as digital leaders. FHJ 2020;7:196-8.

8 Maguire J. Digital health - a trainee's perspective. FHJ 2020;7: 202-3.

9 Chen Y, Banerjee A. Improving the digital health of the workforce in the COVID-19 context: an opportunity to future-proof medical training. FHJ 2020;7:189-92. 